\title{
Conscious Sedation by Midazolam and Ketamine in Pediatric Dentistry - A Review
}

\author{
Sarvesh Kumar J', Mahesh Ramakrishnan ${ }^{2}$ and Murugaiyan Arun ${ }^{3}$ \\ ${ }^{1}$ Saveetha Dental College and Hospitals Saveetha Institute of Medical and \\ Technical Sciences Saveetha University, Chennai-77, India \\ ${ }^{2}$ Reader Department of Pedodontics and Preventive Dentistry Saveetha Dental College and Hospitals \\ Saveetha Institute of Medical and Technical Sciences Saveetha University, Chennai-77, India \\ ${ }^{3}$ Senior lecturer Department of Oral and maxillofacial surgery Saveetha Dental College and Hospitals \\ Saveetha Institute of Medical and Technical Sciences Saveetha University, Chennai-77, India
}

\section{ABSTRACT}

Management of an uncooperative behaviour is important in treating a child in a dental office. Young, uncooperative children needing extensive dental treatment are difficult to manage, for these children, conscious sedation or general anesthesia are the primary treatment options that allow comprehensive restorative dental care. To control the pain and anxiety in pedodontic patients, pharmacologic sedation like anesthesia and analgesia are commonly used. Safe sedation of a pediatric patient requires a thorough knowledge of the pharmacokinetics and pharmacodynamics of the drugs used to sedate the patient and the skills necessary to deal effectively with potential adverse events as a result of the sedation. conscious sedation can be very supportive in allying anxiety, uneasiness, fear and minimizing an uncooperative child's attempt to resist treatment procedures. There are a variety of drugs available that can be used for conscious sedation for dental office procedures. Pediatric sedation technique should ideally be customized for the patient and the procedure to be performed. The present review discusses the various aspects of conscious sedation and its application in pediatric dentistry

\section{INTRODUCTION}

Management of children for various dental procedures in dental offices is very challenging. The behavioral problems are commonly seen in children under the age of 6 years due to various elements such as immature reasoning, restricted coping skills and anxiety(Henry and Jerrell, 1990; Swetah and Ramakrishnan, 2019). Conscious sedation is defined as a controlled state

\section{ARTICLE INFORMATION}

${ }^{*}$ Corresponding Author: mahesh@saveetha.com

Received 12th June 2020 Accepted after revision 3rd August 2020

Print ISSN: 0974-6455 Online ISSN: 2321-4007 CODEN: BBRCBA

Thomson Reuters ISI Web of Science Clarivate Analytics USA and Crossref Indexed Journal

\section{Clarivate}

NAAS Journal Score 2020 (4.31) SJIF: 2020 (7.728)

A Society of Science and Nature Publication,

Bhopal India 2020. All rights reserved.

Online Contents Available at: http//www.bbrc.in/

Doi: http://dx.doi.org/10.21786/bbrc/13.7/40 of low consciousness that conserves protective and unconditioned reflexes, permits continuance of a patient's airway impartially and allows the patient to communicate appropriately to physical and verbal stimuli(Kauffman et al., 1992).

Procedural conscious sedation includes providing an adequate level/degree of sedation whereas decreasing pain and anxiety, maximizing amnesia, curtailing the potential for adverse drug-related events, monitoring and governing behavior, and sustaining a stable cardiovascular and respiratory status. Sedation drugs can be administered through various routes such as oral, inhalational, nasal, intramuscular, subcutaneous, and intravenous routes(Mistry and Nahata, 2005).

The primary use of pharmacological sedation is to modify or eliminate negative behavior and allow the child to

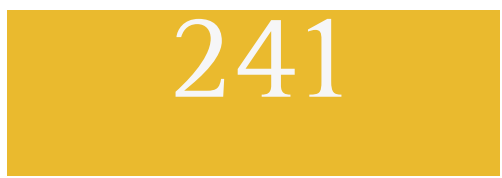


cooperate(McComb et al., 2002),improve the patient's behavior, reduce apprehension, minimize the negative psychological response toward treatment by reducing anxiety, and maximize amnesia potential so as to control behavior during dental procedure.(Coté, 2001) Sedative drugs may be administered by oral, inhalation, rectal, submucosal, intramuscular, or intravenous routes. The selection of techniques is often made as a matter of clinical judgment. Oral sedation is regarded by many dentists to be the simplest and most convenient sedation method for managing uncooperative children, since it is easy to administer and there is no need for nasal hood or injection.(Wright and McAulay, 1973).

Our department is passionate about child care, we have published numerous high quality articles in this domain over the past 3 years (Govindaraju et al., 2017a, 2017b; Jeevanandan et al., 2019; Jeevanandan and Govindaraju, 2018; Nair et al., 2018; Panchal et al., 2017; Veerale Panchal et al., 2019; V. Panchal et al., 2019; Ramadurai et al., 2019; Ramakrishnan et al., 2019; Ravikumar et al., 2017, 2018, 2019; Ravindra et al., 2018, 2019; Samuel et al., 2020; Subramanyam et al., 2018; Vignesh et al., 2019; Vishnu Prasad et al., 2018). With this inspiration the present review was conducted to discuss the advantages of conscious sedation by midazolam and ketamine in pediatric dentistry.

Sedative Drugs: The use of sedative drugs alongside local anesthesia is often appropriate to reduce anxiety and fear among patients. There are a number of sedative drugs that can be used for dental procedures, midazolam belongs to benzodiazepine groups that is used as a short and fast acting drug prior to general anesthesia or several other medical diagnostic approaches(Golpayegani et al., 2012). On the other hand, several other studies(Chudnofsky et al., 2000; Karapinar et al., 2006; Sener et al., 2011; Shende et al., 2003; Warner et al., 1995), have looked at the sedative effects of similar drugs used along with midazolam with a synergic effect to reduce the required dose of midazolam. Ketamine and midazolam combination has already been used successfully for the surgical treatment of young fearful and anxious children (Chudnofsky et al., 2000; Golpayegani et al., 2012; Sener et al., 2011).

Midazolam: The resultant effects of midazolam in children under sedation for dental procedures have been studied in a number of projects, and midazolam is now the standard agent for conscious sedation during pedodontic treatments (Erlandsson et al., 2001; Jensen, 2002; Jensen and Matsson, 2002; Lindh-Strömberg, 2001; Yanase et al., 2009). Midazolam is a short-acting benzodiazepine with quick onset, shorter term of activity and negligible symptoms. The intramuscular prescribed amount (used for premedication) is $0.07-0.08 \mathrm{mg} / \mathrm{kg}$; the intravenous measured quantity for tranquility is $0.07-0.1 \mathrm{mg} / \mathrm{kg}$, titrated according to response; the oral amount for tranquility/drowsiness is $0.2 \mathrm{mg} / \mathrm{kg}$. The end point for sedation is drowsiness and slurring of speech - response to commands is maintained (Butler, 2006; Sasada and Smith, 1997). Diazepam and midazolam exhibit similar sedative effects, but the latter provides a better anxiolytic effect as well as a minimally higher level of sedation; therefore, diazepam does not offer any sedative advantage over midazolam(Tyagi et al., 2013).

Midazolam-mode of action: The mode of action of benzodiazepines (midazolam) is thought to act through specific benzodiazepine receptors found all around the central nervous system (CNS) and focal sensory system. Benzodiazepine receptors are completely joined with gamma amino butyric acid (GABA) receptors. GABA receptors open chloride particle channels, which hyperpolarize and produce hypnosis and sedation (Butler, 2006; Sasada and Smith, 1997).

Ketamine: Ketamine is an $\mathrm{N}$-methyl d-aspartate (NMDA) opponent which prompts a daze like sedation with few considerable impacts (Karapinar et al., 2006; Shende et al., 2003; Warner et al., 1995). Ketamine is a dissociative agent that gives sedation, control of pain and amnesia(Rodriguez and Jordan, 2002). Ketamine is used for the induction of anesthesia, especially in high risk patients with hypotension or asthma, for short procedures it is the fundamental technique, for instance; intra-visual examinations, burns dressings and radiological and radiotherapy procedures in children, as an agent for mass casualties in the field, for analgesia both post-operatively and in patients receiving intensive care, for pain relief from chronic pain for patients and for the reversal of severe unresponsive asthma(Sasada and Smith, 1997).

Ketamine-mode of action: Ketamine is a non-competitive antagonist of the N-methyl-d-aspartate (NMDA) receptors $\mathrm{Ca}^{2+}$ channel pore and also inhibits NMDA receptor activity by interaction with phencyclidine binding sites. It may also modulate opioid and muscarinic activity. Ketamine causes tachycardia, an increase in the blood pressure, central venous pressure and cardiac output secondary to enhance sympathetic tone. It causes mild stimulation of respiration with relative reservation of airway reflexes. Bronchodilation is a feature of the action of the drug. The state of dissociative anesthesia is produced by ketamine. The cerebral blood flow, cerebral metabolic rate, intraocular pressure increased; amnesia is a marked feature. At high doses, ketamine exhibits local anesthetic properties(Nagdeve et al., 2006; Sasada and Smith, 1997).

Ketamine and Midazolam combination: Ketamine and Midazolam have been utilized independently to encourage the sedation of painful techniques for pediatric patients(Sievers et al., 1991; Tobias et al., 1992). However, benzodiazepine sedation does not give a pain relieving impact and is deficient to anticipate pain emulated by additional combative techniques for example central venous catheter insertion or bone marrow biopsy. It was demonstrated that the combination of ketamine with midazolam gave faster onset of absence of pain and much proficient amnesia, diminishing the obliged dosage of ketamine and the occurrence of illusions(Beebe et al., 1992; Okamoto et al., 1992). when comparing 
oral midazolam and oral ketamine, while they exhibit similar sedative effects, midazolam is more conducive to anxiolysis, and orally administered ketamine results in a slower recovery period post-sedation(Damle et al., 2008).

\section{Routes of Drug Administration}

Intravenous and intramuscular route: Diazepam's absorption after IM injection is slow and erratic and it is often associated with severe pain(Bergman et al., 1988), whereas midazolam is well-absorbed and is less painful via the IM route. When administered intravenously, diazepam may cause phlebitis and local pain, whereas midazolam does not, due to its increased water solubility. The recommended dose for IV administration of midazolam is between $0.05-0.1 \mathrm{mg} / \mathrm{kg}$, depending on the nature of the procedure and whether other drugs are being used(Diament and Stanley, 1988; Tolia et al., 1990, 1991). Intravenous ketamine has been shown to have a powerful sedative effect; some researchers actually preferred ketamine to midazolam due to increased patient cooperativeness and because it carried less side effects. (Rai et al., 2007)

Oral route: Numerous studies of oral midazolam in children have given conflicting results.(Feld et al., 1990; Payne et al., 1991) A single oral dose of $0.2 \mathrm{mg} /$ $\mathrm{kg}$ was found to be effective during laceration repair in the emergency room(Hennes et al., 1990). However, most studies indicated that a higher oral dose is needed (Silver, 1992). Only 15-30\% of an orally administered dose reaches the systemic circulation in its non metabolized form due to an extensive first pass hepatic effect, Thus, the oral dose should be approximately double or triple the intravenous dose to achieve similar clinical effects(Payne et al., 1989). oral administration of ketamine has also been studied using a lollipop to deliver the drug, and its effectiveness was then compared with oral midazolam without evidence of any greater sedative effects(Horiuchi et al., 2005).

Rectal route: Oral administration requires patient cooperation, whereas the rectal route does not. Children could be told that their temperature is being taken and frequently they will cooperate for the procedure. Most drugs, however, are not as well-absorbed rectally as from the upper intestine(Holroyd et al., 1988). Rectal midazolam has been studied as a preanesthetic medication for children and the optimal sedative dose was determined to be $1.0 \mathrm{mg} / \mathrm{kg}$ (Spear et al., 1991).

Nasal Route: Ketamine can be delivered safely and effectively via an intranasal route of administration (Bhatnagar et al., 2008). Ketamine also proves very useful when administered intranasally, inducing a high level of sedation. Children sedated with intranasal midazolam are passive and moderately drowsy but usually do not fall completely asleep. The average time to peak plasma concentrations and maximal effect is $10 \mathrm{~min}$ (Latson et al., 1991; Rose et al., 1990) and recovery time is approximately $30 \mathrm{~min}$, with the degree of the sedative effect similar to that obtained with IM administration (de Santos et al., 1991). Intranasal midazolam may be used in combination with other drugs in diagnostic and short surgical procedures in children. One technique involved $0.2 \mathrm{mg} / \mathrm{kg}$ intranasal midazolam followed by $9.0 \mathrm{mg} / \mathrm{kg}$ ketamine administered rectally(Saint-Maurice et al., 1990).

Adverse Effects: Side effects of midazolam confined to occasional discomfort at the site of injection. Withdrawal phenomena may occur in children after prolonged infusion(Kain et al., 2000). In case of any unwanted event, antidote for midazolam (Flumazenil) can be administered intravenously ( $0.01 \mathrm{mg} / \mathrm{kg} / \mathrm{dose})$.The dose can be repeated for up to four times with an interval of one minute each(Adams and Dervay, 2012; Khalid et al., 2011). Emergence delirium, unpleasant dreams and hallucinations are much notable complications of the use of ketamine(Sasada and Smith, 1997; Webster and Walker, 2006). Transitory depression of breath and apnea can be seen after administration of ketamine either intramuscularly or intravenous(S. M. Green et al., 1998; Steven M. Green et al., 1998; Zsigmond et al., 1976). The benzodiazepine group of drugs is one of the safest presently in use. Midazolam is virtually free of any side effects.

The major risk associated with high doses of midazolam is hypoventilation and associated hypoxemia(Sievers et al., 1991). Respiratory depression has been reported in adults(Lewis and Benjamin, 1990), however, there have been few reports of depression in children. Children receiving midazolam should be monitored for early signs of hypoventilation or apnea. Respiratory depression appears to be dose related(Reves et al., 1985), and dosage regimens should be strictly followed (Sievers et al., 1991).

The increase in muscle tone produced by ketamine makes it unsuitable for operations where muscle relaxation is needed(Kolawole, 2001). The increase in salivation produced by ketamine can be troublesome during dental procedures and premedication with an antisialogogue may be needed (Dundee and Wyant, 1974). Patients have reported disturbing sensations when awakening from ketamine anesthesia. Ketamine can cause an increase in blood pressure and intracranial pressure, or pressure in the brain. Ulcerative cystitis, secondary renal damage and hepatic failure can occur with high doses of oral ketamine (Bell, 2009).

\section{CONCLUSION}

Midazolam offers many advantages when compared with diazepam, which are, it is more water soluble, rapid onset, short acting, anticonvulsant, muscle relaxant, relatively high margin of safety, reversal agent available and can be administered intranasally and when given intravenously, it is less irritating and causes fewer adverse local vascular reactions and pain. Its distribution and elimination halflives are much shorter than with diazepam. Evidences provided strong, positive evidence for the use of ketamine 
alone or in combination with midazolam to reduce dental anxiety and behavioral non-compliance

\section{REFERENCES}

Adams D and Dervay KR (2012) Pharmacology of procedural sedation. AACN advanced critical care 23(4): 349-54; quiz 355-6.

Beebe DS, Belani KG, Chang PN, et al. (1992) Effectiveness of preoperative sedation with rectal midazolam, ketamine, or their combination in young children. Anesthesia and analgesia 75(6): 880-884.

Bell RF (2009) Ketamine for chronic non-cancer pain. Pain 141(3): 210-214.

Bergman SA, Wynn RL, Roth-Schechter BF, et al. (1988) The benzodiazepines, sedative-hypnotics, and central muscle relaxants. Clinical Pharmacology in Dental Practice, 4th Ed. SV Holroyd, RL Wynn, B Requa-Clark, EDS. St. Louis: CV Mosby Co: 82-90.

Bhatnagar S, Mishra S, Gupta M, et al. (2008) Efficacy and safety of a mixture of ketamine, midazolam and atropine for procedural sedation in paediatric oncology: a randomised study of oral versus intramuscular route. Journal of paediatrics and child health 44(4): 201-204.

Butler T (2006) Central and peripheral benzodiazepine receptors. Epilepsia.

Chudnofsky CR, Weber JE, Stoyanoff PJ, et al. (2000) A combination of midazolam and ketamine for procedural sedation and analgesia in adult emergency department patients. Academic emergency medicine: official journal of the Society for Academic Emergency Medicine 7(3): 228-235.

Coté CJ (2001) Anesthesia outside the operating room. A practice of anesthesia for infants and children, 3rd ed. Philadelphia: WB Saunders: 571-583.

Damle SG, Gandhi M and Laheri V (2008) Comparison of oral ketamine and oral midazolam as sedative agents in pediatric dentistry. Journal of the Indian Society of Pedodontics and Preventive Dentistry 26(3): 97-101. de Santos P, Chabás E, Valero R, et al. (1991) [Comparison of intramuscular and intranasal premedication with midazolam in children]. Revista espanola de anestesiologia y reanimacion 38(1): 12-15.

Diament MJ and Stanley P (1988) The use of midazolam for sedation of infants and children. American Journal of Roentgenology 150(2). American Roentgen Ray Society: 377-378.

Dundee JW and Wyant GM (1974) Intravenous Anaesthesia. Churchill Livingstone.

Erlandsson AL, Bäckman B, Stenström A, et al. (2001) Conscious sedation by oral administration of midazolam in paediatric dental treatment. Swedish dental journal 25(3): 97-104.

Feld LH, Negus JB and White PF (1990) Oral midazolam preanesthetic medication in pediatric outpatients. Anesthesiology 73(5): 831-834.

Golpayegani MV, Dehghan F, Ansari G, et al.
(2012) Comparison of oral Midazolam-Ketamine and Midazolam-Promethazine as sedative agents in pediatric dentistry. Dental research journal 9(1): 36-40.

Govindaraju L, Jeevanandan G and Subramanian EMG (2017a) Comparison of quality of obturation and instrumentation time using hand files and two rotary file systems in primary molars: A single-blinded randomized controlled trial. European journal of dentistry 11(3): 376-379.

Govindaraju L, Jeevanandan G and Subramanian EMG (2017b) Knowledge and practice of rotary instrumentation in primary teeth among indian dentists: A questionnaire survey. Journal of International Oral Health 9(2): 45.

Green S. M., Rothrock SG, Lynch EL, et al. (1998) Intramuscular ketamine for pediatric sedation in the emergency department: safety profile in 1,022 cases. Annals of emergency medicine 31(6): 688-697.

Green Steven M., Rothrock SG, Harris T, et al. (1998) Intravenous Ketamine for Pediatric Sedation in the Emergency Department: Safety Profile with 156 Cases. Academic Emergency Medicine. DOI: 10.1111/j.15532712.1998.tb02773.x.

Hennes HM, Wagner V, Bonadio WA, et al. (1990) The effect of oral midazolam on anxiety of preschool children during laceration repair. Annals of emergency medicine 19(9): 1006-1009.

Henry RJ and Jerrell RG (1990) Ambient nitrous oxide levels during pediatric sedations. Pediatric dentistry 12(2): 87-91.

Holroyd SV, Wynn RL and Requa-Clark B (1988) Clinical Pharmacology in Dental Practice. Mosby Incorporated.

Horiuchi T, Kawaguchi M, Kurehara K, et al. (2005) Evaluation of relatively low dose of oral transmucosal ketamine premedication in children: a comparison with oral midazolam. Paediatric anaesthesia 15(8): 643-647.

Jeevanandan G and Govindaraju L (2018) Clinical comparison of Kedo-S paediatric rotary files vs manual instrumentation for root canal preparation in primary molars: a double blinded randomised clinical trial. European archives of paediatric dentistry: official journal of the European Academy of Paediatric Dentistry 19(4): 273-278.

Jeevanandan G, Ganesh S and Arthilakshmi (2019) Kedo file system for root canal preparation in primary teeth. Indian journal of dental research: official publication of Indian Society for Dental Research 30(4): 622-624. Jensen B (2002) Benzodiazepine sedation in paediatric dentistry. Swedish dental journal. Supplement (153): $1-45$.

Jensen B and Matsson L (2002) Oral versus rectal midazolam as a pre-anaesthetic sedative in children receiving dental treatment under general anaesthesia. Acta Pædiatrica 91(8). Wiley Online Library: 920-925. Kain ZN, Hofstadter MB, Mayes LC, et al. (2000) 
MidazolamEffects on Amnesia and Anxiety in Children. Anesthesiology 93(3). The American Society of Anesthesiologists: 676-684.

Karapinar B, Yilmaz D, Demirag K, et al. (2006) Sedation with intravenous ketamine and midazolam for painful procedures in children. Pediatrics international: official journal of the Japan Pediatric Society 48(2): 146-151. Kauffman RE, Banner W, Berlin CM, et al. (1992) Guidelines for monitoring and management of pediatric patients during and after sedation for diagnostic and therapeutic procedures. Pediatrics 89(6). American Academy of Pediatrics: 1110-1115.

Khalid 0, Srivastava R, Mulhall A, et al. (2011) Conscious sedation: is it always needed for endoscopy? Practical gastroenterology 35(2): 10-15.

Kolawole IK (2001) Ketamine Hydrochloride: A Useful but Frequently Misused Drug. Nigerian Journal of Surgical Research 3(3): 118-125.

Latson LA, Cheatham JP, Gumbiner CH, et al. (1991) Midazolam nose drops for outpatient echocardiography sedation in infants. American heart journal 121(1 Pt 1): 209-210.

Lewis JH and Benjamin SB (1990) Safety of midazolam and diazepam for conscious sedation. Journal of clinical gastroenterology.

Lindh-Strömberg U (2001) Rectal administration of midazolam for conscious sedation of uncooperative children in need of dental treatment. Swedish dental journal 25(3): 105-111.

McComb M, Koenigsberg SR, Broder HL, et al. (2002) The effects of oral conscious sedation on future behavior and anxiety in pediatric dental patients. Pediatric dentistry 24(3): 207-211.

Mistry RB and Nahata MC (2005) Ketamine for conscious sedation in pediatric emergency care. Pharmacotherapy 25(8): 1104-1111.

Nagdeve NG, Yaddanapudi S and Pandav SS (2006) The effect of different doses of ketamine on intraocular pressure in anesthetized children. Journal of pediatric ophthalmology and strabismus 43(4): 219-223.

Nair M, Jeevanandan G, Vignesh R, et al. (2018) Comparative evaluation of post-operative pain after pulpectomy with k-files, kedo-s files and mtwo files in deciduous molars -a randomized clinical trial. Brazilian Dental Science 21(4): 411.

Okamoto GU, Duperon DF and Jedrychowski JR (1992) Clinical evaluation of the effects of ketamine sedation on pediatric dental patients. The Journal of clinical pediatric dentistry 16(4): 253-257.

Panchal V, Gurunathan D and Shanmugaavel AK (2017) Smartphone application as an aid in determination of caries risk and prevention: A pilot study. European journal of dentistry 11(4): 469-474.

Panchal Veerale, Jeevanandan G and Subramanian E (2019) Comparison of instrumentation time and obturation quality between hand K-file, H-files, and rotary Kedo-S in root canal treatment of primary teeth:
A randomized controlled trial. Journal of the Indian Society of Pedodontics and Preventive Dentistry 37(1): 75-79.

Panchal V., Jeevanandan G and Subramanian EMG (2019) Comparison of post-operative pain after root canal instrumentation with hand $\mathrm{K}$-files, $\mathrm{H}$-files and rotary Kedo-S files in primary teeth: a randomised clinical trial. European archives of paediatric dentistry: official journal of the European Academy of Paediatric Dentistry 20(5): 467-472.

Payne K, Mattheyse FJ, Liebenberg D, et al. (1989) The pharmacokinetics of midazolam in paediatric patients. European journal of clinical pharmacology 37(3): 267-272.

Payne KA, Coetzee AR and Mattheyse FJ (1991) Midazolam and amnesia in pediatric premedication. Acta anaesthesiologica Belgica 42(2): 101-105.

Rai K, Hegde AM and Goel K (2007) Sedation in uncooperative children undergoing dental procedures: a comparative evaluation of midazolam, propofol and ketamine. The Journal of clinical pediatric dentistry 32(1): 1-4.

Ramadurai N, Gurunathan D, Samuel AV, et al. (2019) Effectiveness of 2\% Articaine as an anesthetic agent in children: randomized controlled trial. Clinical oral investigations 23(9): 3543-3550.

Ramakrishnan M, Dhanalakshmi R and Subramanian EMG (2019) Survival rate of different fixed posterior space maintainers used in Paediatric Dentistry - A systematic review. The Saudi dental journal 31(2): 165-172.

Ravikumar D, Jeevanandan G and Subramanian EMG (2017) Evaluation of knowledge among general dentists in treatment of traumatic injuries in primary teeth: A cross-sectional questionnaire study. European journal of dentistry 11(2): 232-237.

Ravikumar D, Gurunathan D, Gayathri R, et al. (2018) DNA profiling of Streptococcus mutans in children with and without black tooth stains: A polymerase chain reaction analysis. Dental research journal 15(5): 334.

Ravikumar D, N S, Ramakrishna M, et al. (2019) Evaluation of McNamara's analysis in South Indian (Tamil Nadu) children between 8-12 years of age using lateral cephalograms. Journal of oral biology and craniofacial research 9(2): 193-197.

Ravindra V, Rekha V, Annamalai S, et al. (2018) A comparative evaluation between dermatoglyphic patterns and different terminal planes in primary dentition. Journal of clinical and experimental dentistry 10(12): e1149-e1154.

Ravindra V, Rekha CV, Annamalai S, et al. (2019) A comparative evaluation between cheiloscopic patterns and the permanent molar relationships to predict the future malocclusions. Journal of clinical and experimental dentistry 11(6): e553-e557.

Reves J dG, Fragen RJ, Vinik HR, et al. (1985) MidazolamPharmacology and Uses. Anesthesiology: The 
Journal of the American Society of Anesthesiologists 62(3). The American Society of Anesthesiologists: 310-324.

Rodriguez E and Jordan R (2002) Contemporary trends in pediatric sedation and analgesia. Emergency medicine clinics of North America 20(1): 199-222.

Rose E, Simon D and Haberer JP (1990) [Premedication with intranasal midazolam in pediatric anesthesia]. Annales francaises d'anesthesie et de reanimation 9(4): 326-330.

Saint-Maurice C, Landais A, Delleur MM, et al. (1990) The use of midazolam in diagnostic and short surgical procedures in children. Acta Anaesthesiologica Scandinavica. DOI: 10.1111/j.1399-6576.1990. tb03180.x.

Samuel SR, Acharya S and Rao JC (2020) School Interventions-based Prevention of Early-Childhood Caries among 3-5-year-old children from very low socioeconomic status: Two-year randomized trial. Journal of public health dentistry 80(1): 51-60.

Sasada MP and Smith SP (1997) Drugs in Anaesthesia and Intensive Care. Oxford University Press.

Sener S, Eken C, Schultz CH, et al. (2011) Ketamine With and Without Midazolam for Emergency Department Sedation in Adults: A Randomized Controlled Trial. Annals of Emergency Medicine. DOI: 10.1016/j. annemergmed.2010.09.010.

Shende D, Darlong V and Asit N (2003) COMBINATION OF ORAL KETAMINE AND MIDAZOLAM FOR PREANAESTHETIC MEDICATION IN PEDIATRIC PATIENTS: LOW DOSE VS HIGH DOSE. Canadian Journal of Anesthesia 50(90001). Can Anes Soc: 27.

Sievers TD, Yee JD, Foley ME, et al. (1991) Midazolam for conscious sedation during pediatric oncology procedures: safety and recovery parameters. Pediatrics 88(6): 1172-1179.

Silver TC (1992) Evaluation of oral midazolam sedation for pediatric dental patients. Pediatric dentistry 14: 413.

Spear RM, Yaster M, Berkowitz ID, et al. (1991) Preinduction of anesthesia in children with rectally administered midazolam. Anesthesiology 74(4): 670674.

Subramanyam D, Gurunathan D, Gaayathri R, et al. (2018) Comparative evaluation of salivary malondialdehyde levels as a marker of lipid peroxidation in early childhood caries. European journal of dentistry 12(1): 67-70.

Swetah CSV and Ramakrishnan M (2019) Dental Anxiety among Children Regarding Different Dental TreatmentModified Child Dental Anxiety Scale (MCDAS)-A Cross Sectional Study. Indian Journal of Public
Health Research \& Development. DOI: 10.5958/09765506.2019.04159.7.

Tobias JD, Phipps S, Smith B, et al. (1992) Oral ketamine premedication to alleviate the distress of invasive procedures in pediatric oncology patients. Pediatrics 90(4): 537-541.

Tolia V, Fleming SL and Kauffman RE (1990) Randomized, double-blind trial of midazolam and diazepam for endoscopic sedation in children. Developmental pharmacology and therapeutics 14(3): 141-147.

Tolia V, Brennan S, Aravind MK, et al. (1991) Pharmacokinetic and pharmacodynamic study of midazolam in children during esophagogastroduodenoscopy. The Journal of pediatrics 119(3): 467-471.

Tyagi P, Tyagi S and Jain A (2013) Sedative effects of Oral Midazolam, Intravenous Midazolam and Oral Diazepam in the Dental Treatment of Children. Journal of Clinical Pediatric Dentistry. DOI: 10.17796/ jcpd.37.3.6u482603r0388558.

Vignesh R, Sharmin D, Rekha CV, et al. (2019) Management of Complicated Crown-Root Fracture by Extra-Oral Fragment Reattachment and Intentional Reimplantation with 2 Years Review. Contemporary clinical dentistry 10(2): 397-401.

Vishnu Prasad S, Kumar M, Ramakrishnan M, et al. (2018) Report on oral health status and treatment needs of 5-15 years old children with sensory deficits in Chennai, India. Special care in dentistry: official publication of the American Association of Hospital Dentists, the Academy of Dentistry for the Handicapped, and the American Society for Geriatric Dentistry 38(1): 58-59.

Warner DL, Cabaret J and Velling D (1995) Ketamine plus midazolam, a most effective paediatric oral premedicant. Paediatric anaesthesia 5(5): 293-295.

Webster LR and Walker MJ (2006) Safety and efficacy of prolonged outpatient ketamine infusions for neuropathic pain. American journal of therapeutics 13(4): 300-305.

Wright GZ and McAulay DJ (1973) Current premedicating trends in pedodontics. ASDC journal of dentistry for children 40(3): 185-187.

Yanase H, Braham RL, Fukuta 0, et al. (2009) A study of the sedative effect of home-administered oral diazepam for the dental treatment of children. International Journal of Paediatric Dentistry. DOI: 10.1111/j.1365263x.1996.tb00202.x.

Zsigmond EK, Matsuki A, Kothary SP, et al. (1976) Arterial Hypoxemia Caused by Intravenous Ketamine. Anesthesia \&t Analgesia. DOI: 10.1213/00000539197605000-00005. 